\section{Pin Ingestion and Upper Endoscopy}

Sharp or pointed foreign bodies may perforate the gastrointestinal tract (1). Among these, nails and pins are most frequent, particularly among prisoners, alcoholics, and mentally retarded people. Foreign bodies of this sort can pass the gastrointestinal tract spontaneously (2).

A non-alcoholic, healthy woman was admitted five hours after swallowing a pin. Upright plain radiographs of the abdomen revealed a pin just anterior to the second lumbar vertebra (Figure 1). It was unclear whether it was in the small bowel, transverse colon, or in the stomach. Upper gastrointestinal endoscopy was not able to locate the pin, which had passed to the descending colon, and probably due to the air insufflated during the endoscopy procedure, the colon was better delineated (Figure 2). The same day, the pin emerged spontaneously. Nevertheless, upper gastrointestinal endoscopy should be carried out in any case of ingestion of a sharp foreign body.

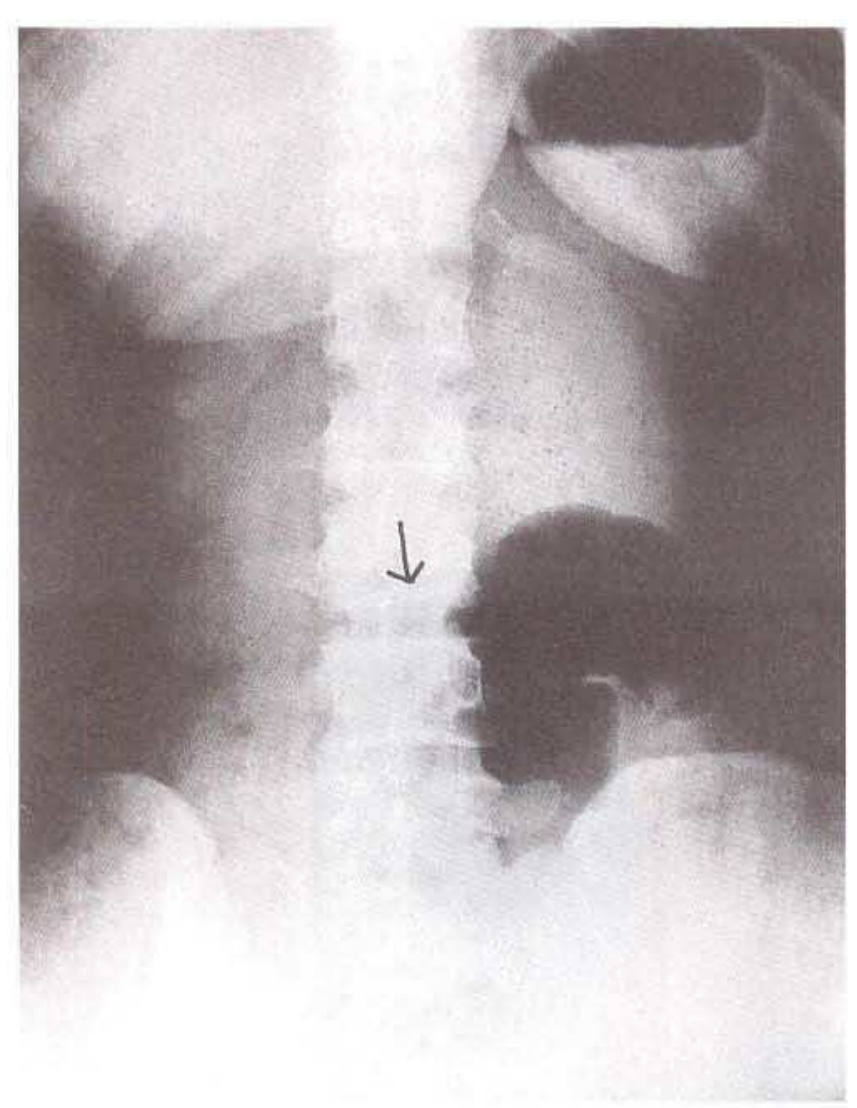

Figure 1: The pin just anterior to the second lumbar vertebra

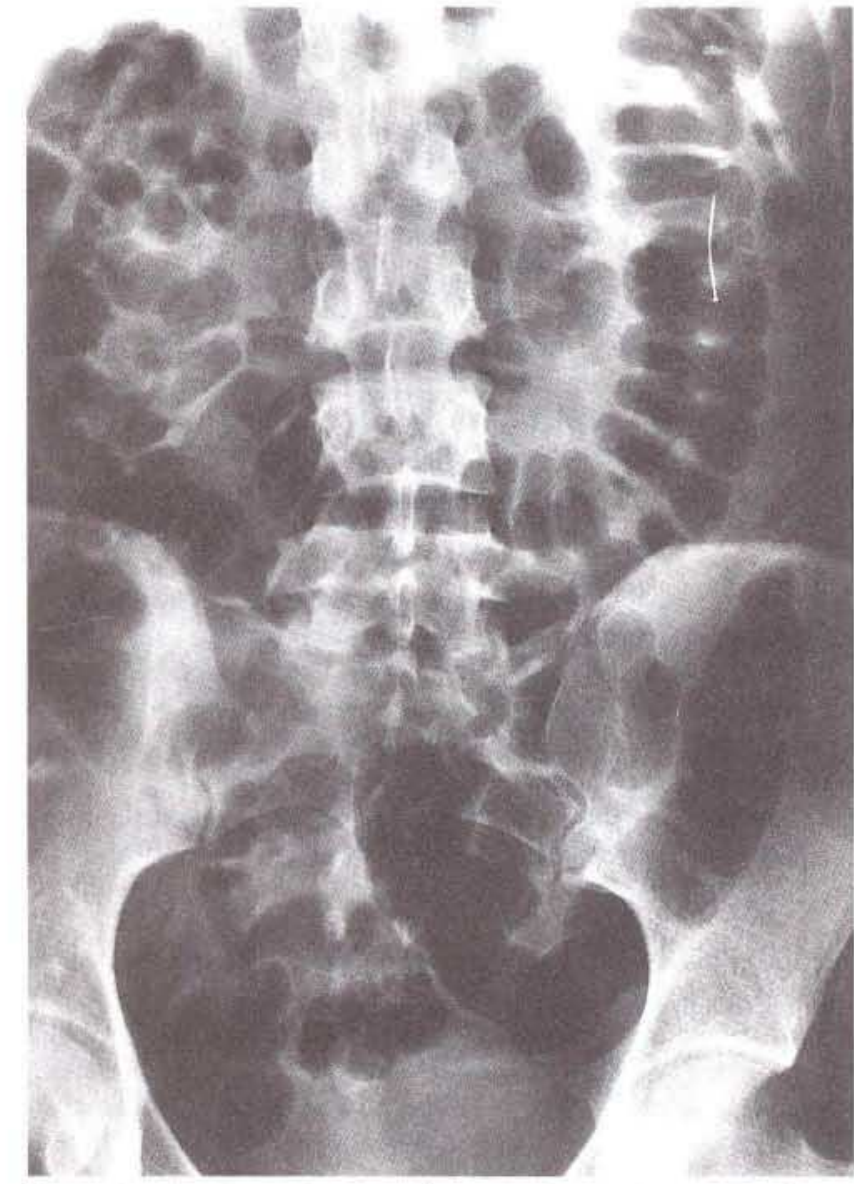

Figure 2: The pin in the descending colon (better visualization due to insufflated air)

G. Oksüzoglu, M. Arslan, G. Tatar

Dept. of Internal Medicine, Gastroenterology Section, Hacettepe Medical School, Ankara, Turkey

\section{References}

1. Buto SK, Tsang TK, Sielaf GW, et al. Bay leaf impaction in the esophagus and hypopharynx. Ann Intern Med 1990; 113: 82.

2. Vizcarrondo FJ, Bradey PG, Nord HJ. Foreign bodies in the upper gastrointestinal tract. Gastrointest Endosc 1983; 29: 208 .

Corresponding Author

G. Öksuzoglu, M.D.

Bardacik Sok. 108/15, 06660

K. Esat

Ankara

Turkey

Fax: $+90-312-2850733$ 